\title{
Oleoylethanolamide Ameliorates Dextran Sulfate Sodium-Induced Colitis in Rats
}

\author{
Shinsuke Otagiri, Shunsuke Ohnishi ${ }^{*}$, Masatsugu Ohara, Qingjie Fu, Koji Yamamoto, \\ Keiko Yamamoto, Takehiko Katsurada and Naoya Sakamoto
}

Department of Gastroenterology and Hepatology, Hokkaido University Graduate School of Medicine, Sapporo, Japan

OPEN ACCESS

Edited by:

Raffaele Capasso,

University of Naples Federico II, Italy

Reviewed by:

Vanessa Souza-Mello,

Rio de Janeiro State University, Brazil

Martin Diener,

University of Giessen, Germany Justin C. Konje,

University of Leicester, United Kingdom

Sinead Corr,

Trinity College Dublin, Ireland

*Correspondence:

Shunsuke Ohnishi

sonishi@pop.med.hokudai.ac.jp

Specialty section:

This article was submitted to

Gastrointestinal and

Hepatic Pharmacology,

a section of the journal

Frontiers in Pharmacology

Received: 02 June 2020 Accepted: 03 August 2020

Published: 14 August 2020

Citation:

Otagiri S, Ohnishi S, Ohara M, Fu Q, Yamamoto K, Yamamoto $K$ Katsurada T and Sakamoto N (2020)

Oleoylethanolamide Ameliorates

Dextran Sulfate Sodium-Induced

Colitis in Rats.

Front. Pharmacol. 11:1277.

doi: 10.3389/fphar.2020.01277
Oleoylethanolamide (OEA) is an endogenous fatty acid ethanolamide known for its antiinflammatory effects and its influence on gut microbiota composition; however, the effects of OEA in inflammatory bowel disease (IBD) remain unknown. During in vitro experiments, OEA downregulated the expression of tumor necrosis factor (TNF)- $\alpha$ and reduced phosphorylation of inhibitor of kappa $(\mid \kappa) \mathrm{B} \alpha$ induced by lipopolysaccharide in human embryonic kidney cells. Moreover, OEA downregulated the expression of interleukin (IL)-8 and IL-1 $\beta$ and inhibited the phosphorylation of $\mathrm{I} \mathrm{KB} \alpha$ and $\mathrm{p} 65$ induced by TNF- $\alpha$ in human enterocytes (Caco-2). The effect of OEA in reducing the expression of IL-8 was blocked by the peroxisome proliferator-activated receptor (PPAR)- $\alpha$ antagonist. During in vivo experiments on rats, colitis was induced by the oral administration of $8 \%$ dextran sulfate sodium from day 0 through day 5 , and OEA $(20 \mathrm{mg} / \mathrm{kg})$ was intraperitoneally injected once a day from day 0 for 6 days. OEA administration significantly ameliorated the reduction in body weight, the increase in disease activity index score, and the shortening of colon length. In rectums, OEA administration reduced the infiltration of macrophages and neutrophils and tended to reduce the histological score and the expression of inflammatory cytokines. Administration of OEA produced significant improvement in a colitis model, possibly by inhibiting the nuclear factor kappa B signaling pathway through PPAR- $\alpha$ receptors. OEA could be a potential new treatment for IBD.

Keywords: oleoylethanolamide, dextran sulfate sodium, inflammatory bowel disease, nuclear factor kappa B, peroxisome proliferator-activated receptor- $\alpha$

\footnotetext{
Abbreviations: CD, Crohn's disease; DAI, disease activity index; DMEM, Dulbecco's modified Eagle's medium; DMSO, dimethyl sulfoxide; DSS, dextran sulfate sodium; FBS, fetal bovine serum; GPR, G protein-coupled receptor; HE, hematoxylin and eosin; IBD, inflammatory bowel disease; Iא inhibitor of kappa; IL, interleukin; LPS, lipopolysaccharide; MPO, myeloperoxidase; NF- $\mathrm{B}$, nuclear factor kappa B; OEA, oleoylethanolamide; PBS, phosphate-buffered saline; PPAR, peroxisome proliferator-activated receptor; qRT-PCR, quantitative reverse transcription-polymerase chain reaction; SD, standard deviation; SDS, sodium dodecyl sulfate; TGF, transforming growth factor; TLR, toll-like receptor; TNF, tumor necrosis factor; TRPV, transient receptor potential vanilloid; UC, ulcerative colitis.
} 


\section{INTRODUCTION}

Inflammatory bowel disease (IBD), which mainly consists of Crohn's disease (CD) and ulcerative colitis (UC), is a chronic inflammatory disorder of the gastrointestinal tract. Due to the development of new therapeutic drugs for IBD in recent decades, such as biological medicines, treatment options have increased (Feagan et al., 2016; Sandborn et al., 2017); however, due to a lack of curative treatment for IBD, many patients remain resistant to medical therapy and require surgery (Peyrin-Biroulet et al., 2010; Fumery et al., 2018). Therefore, new therapeutic options for IBD are needed.

Oleoylethanolamide (OEA) is an endogenous fatty acid ethanolamide belonging to the $\mathrm{N}$-acylethanolamine family. OEA is contained in foods such as nuts, cocoa powder, and oatmeal (Payahoo et al., 2019), and has been found in different tissues such as the gastrointestinal tract, muscle, adipocytes, liver, kidney, heart, lung, pancreas, brain, salivary gland, and reproductive tract (Ambrosini et al., 2006; Tutunchi et al., 2020). OEA activates peroxisome proliferator-activated receptor (PPAR)- $\alpha, G$ protein-coupled receptor (GPR) 119, and transient receptor potential vanilloid (TRPV) 1 (Brown et al., 2016). Previous studies have demonstrated that the administration of OEA has therapeutic effects on modulating feeding, lipid metabolism, and gastrointestinal motility (Cluny et al., 2009; Decara et al., 2012; Fu and Gaetani, 2013). Other studies have demonstrated that OEA has neuroprotective and antiatherosclerotic functions (Fan et al., 2014; Gonzalez-Aparicio et al., 2017). OEA has also been receiving attention for its antiinflammatory effects and its effect on gut microbiota composition (Di Paola et al., 2018; Yang et al., 2016). A study on humans has shown that plasma OEA levels are elevated in patients with $\mathrm{CD}$, and that these levels correlate with disease severity (Grill et al., 2019), suggesting a role for OEA in reinstating homeostasis. However, the effects and roles of OEA administration in IBD remain unknown.

Thus, the aim of this study was to examine the effects of OEA on colitis in rats and to investigate their underlying mechanisms.

\section{MATERIALS AND METHODS}

\section{Reagents}

OEA and MK866, a PPAR- $\alpha$ antagonist, were purchased from Cayman Chemical (Ann Arbor, MI, USA). OEA was dissolved in dimethyl sulfoxide (DMSO, Wako Pure Chemical Industries, Osaka, Japan) for the in vitro experiments and was dissolved in a vehicle composed of Tween 80 (Kanto Chemical, Tokyo, Japan), DMSO, and phosphate-buffered saline (PBS, Life Technologies, Carlsbad, CA, USA) (1:0.5:18.5 by volume) for the in vivo experiments.

\section{Cell Culture}

Caco-2 cells (human intestinal epithelial cells) were purchased from RIKEN BioResource Center (Tsukuba, Japan). The cells were cultured in Dulbecco's modified Eagle's medium (DMEM, Thermo Fisher Scientific, Waltham, MA, USA) containing 10\% fetal bovine serum (FBS, Moregate Biotech, Bulimba, Australia), $100 \mathrm{U} / \mathrm{ml}$ penicillin, and $100 \mu \mathrm{g} / \mathrm{ml}$ streptomycin (Wako Pure Chemical Industries); and 1\% MEM non-essential amino acids solution (Wako Pure Chemical Industries), and was maintained at $37^{\circ} \mathrm{C}$ in a humidified atmosphere of $5 \% \mathrm{CO}_{2}$. The medium was changed every other day. Caco-2 cells were activated by human recombinant tumor necrosis factor (TNF)- $\alpha$ (Merck Millipore, Burlington, MA, USA). Human embryonic kidney cells (HEK293, RIKEN BioResource Center) or their derivatives, which were stably transfected with the human toll-like receptor (TLR) 4a, MD2, and CD14 genes (293/hTLR4A-MD2-CD14; InvivoGen, San Diego, CA, USA), were cultured in DMEM containing $10 \%$ FBS, $100 \mathrm{U} / \mathrm{ml}$ penicillin, and $100 \mu \mathrm{g} / \mathrm{ml}$ streptomycin. The 293/hTLR4A-MD2-CD14 cells were activated by lipopolysaccharide (LPS, Sigma-Aldrich, St. Louis, MO, USA).

\section{Western Blot Analysis}

To investigate phosphorylation of the inhibitor of kappa (Iא) $\mathrm{B} \alpha$ and p65, Caco-2 cells and 293/hTLR4A-MD2-CD14 cells were plated into 6-well plates $\left(2 \times 10^{5}\right.$ cells/well; Corning, NY, USA) and cultured. After the cells became nearly confluent, the culture medium was changed to a medium containing OEA $(40 \mu \mathrm{M})$ or DMSO, and the cells were incubated for an additional $30 \mathrm{~min}$. The cells were then treated with $5.0 \mathrm{ng} / \mathrm{ml}$ TNF- $\alpha$ for $15 \mathrm{~min}$ or $10 \mathrm{ng} / \mathrm{ml}$ LPS for $2 \mathrm{~h}$ and were washed with ice-cold PBS. Cell lysates were prepared using a radioimmunoprecipitation assay buffer containing $50 \mathrm{mM}$ Tris- $\mathrm{HCl}(\mathrm{pH} 8.0), 150 \mathrm{mM} \mathrm{NaCl}, 0.5 \%$ $(\mathrm{w} / \mathrm{v})$ sodium deoxycholate, $0.1 \%(\mathrm{w} / \mathrm{v})$ sodium dodecyl sulfate (SDS), $1.0 \%(\mathrm{w} / \mathrm{v})$ NP-40 substitute, and Protease/Phosphatase Inhibitor Cocktail (Cell Signaling Technology, Beverly, MA, USA). Equal amounts of cellular protein extracts were diluted in a $4 \times$ Laemmli sample buffer (Bio-Rad, Hercules, CA, USA). The samples were heated at $95^{\circ} \mathrm{C}$ for $5 \mathrm{~min}$, then underwent SDSpolyacrylamide gel electrophoresis (Bio-Rad). The separated proteins were transferred to Immobilon-P polyvinylidene difluoride membranes (Merck Millipore), which were subsequently incubated in tris-buffered saline with $0.05 \%$ Tween 20 (Wako Pure Chemical industries) consisting of a 5\% PhosphoBLOCKER blocking reagent (Cell Biolabs, San Diego, CA, USA) at room temperature for $60 \mathrm{~min}$. The membranes were probed with primary antibodies for phosphoI $\mathrm{B} \alpha \alpha$ (1:2,000; Cell Signaling Technology), I $\mathrm{I} B \alpha(1: 2,000$; Cell Signaling Technology), phospho-p65 (1:2,000; Cell Signaling Technology), and nuclear factor kappa B (NF-кB, 1:2,000; Cell Signaling Technology); actin (1:2,000; Abcam, Cambridge, UK) and bound antibodies were detected with peroxidase AffiniPure Goat Anti-Mouse IgG (H+L) (1:10,000; Jackson ImmunoResearch, West Grove, PA, USA) or peroxidase AffiniPure Goat Anti-Rabbit $\operatorname{IgG}(\mathrm{H}+\mathrm{L})$ (1:10,000; Jackson ImmunoResearch), and visualized and photographed using ECL Prime detection reagent (GE Healthcare, Chicago, IL, USA). The blots were analyzed using Fusion Solo S (Vilber Lourmat, Marne-la-Vallée, France).

\section{Animals}

Eight-week-old male Sprague-Dawley rats were procured from Japan SLC (Hamamatsu, Japan), and one rat was housed per cage in a temperature-controlled room $\left(24^{\circ} \mathrm{C}\right)$ on a $12 \mathrm{~h} \mathrm{light} / 12 \mathrm{~h}$ 
dark cycle. All rats had ad libitum access to standard pellets. We measured body weight, scored fresh feces for consistency, and observed bleeding each day to calculate the disease activity index (DAI) as described in Table 1 (Pandurangan et al., 2015).

\section{Induction of Colitis and OEA Treatment}

Colitis in the DSS group and the DSS + OEA group was induced by oral administration of $8 \%$ dextran sulfate sodium (DSS, M.W. = 36,000 - 50,000; MP Biomedicals, Solon, OH, USA) through drinking water from day 0 through day 5 (Figure 1) (Martin et al., 2016). The control group and the OEA group rats had ad libitum access to water. OEA (20 mg/kg) was intraperitoneally injected once a day from day 0 for 6 days to the OEA group and the DSS + OEA group. The control group and the DSS group were treated with DMSO. The dose of OEA was based on previously reported studies (Gaetani et al., 2003; Proulx et al., 2005).

\section{Histological Examination}

The rats were euthanized after 6 days of DSS and OEA treatment. The colon was excised and we cut a fragment of distal colon for about $3 \mathrm{~cm}$ and carefully opened it. Then, we longitudinally cut the $3 \mathrm{~cm}$ fragment for $2 \mathrm{~mm}$ in width for quantitative reverse transcription-polymerase chain reaction (qRT-PCR). The rest of the fragment was used for histological examinations. The fragment was fixed in $40 \mathrm{~g} / \mathrm{L}$ of formaldehyde saline, embedded in paraffin, and cut into $5 \mu \mathrm{m}$ sections. Tissue sections were stained with hematoxylin and eosin (HE). Parameters of inflammation severity, inflammation extent, crypt damage, and percent involvement (percentage of damage area in the fragment) were scored in a blinded fashion. Then, the sum of these three scores (inflammation severity, inflammation extent, crypt damage) was multiplied by percent involvement $(0 \%$; $\times 0$, $1-25 \%$; $\times 1,26-50 \% ; \times 2,51-75 \% ; \times 3,75-100 \% ; \times 4)$ as described in Table 2 (Singh et al., 2011; Onishi et al., 2015).

\section{Immunohistochemical Examination}

To assess macrophage infiltration, the tissue sections were stained with anti-rat CD68 monoclonal antibody (1:100; AbD Serotec, Kidlington, UK) for $60 \mathrm{~min}$ at room temperature. To assess neutrophil infiltration, the tissue sections were stained with anti-rat myeloperoxidase (MPO) antibody (1:300, Thermo Fisher Scientific) overnight at $4^{\circ} \mathrm{C}$. We photographed 10 random fields on a section from each rat and measured the ratio of stained areas in the mucosal layer using a digital image analyzer (WinROOF, Mitani Co., Fukui, Japan).

TABLE 1 | Assessment of DAl. (Pandurangan et al., 2015).

\begin{tabular}{lcll} 
Score & Weight loss & Stool consistency & \multicolumn{1}{c}{ Bleeding } \\
\hline 0 & No loss & Normal & No blood \\
1 & $1-5 \%$ & & \\
2 & $5-10 \%$ & Loose stool & Visual pellet bleeding \\
3 & $10-20 \%$ & & \\
4 & $>20 \%$ & Diarrhea & Gross bleeding/Blood around anus
\end{tabular}

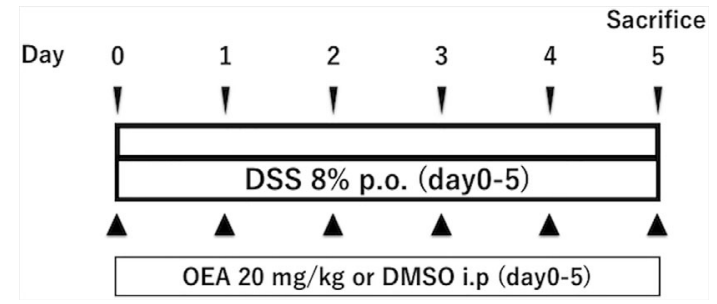

FIGURE 1 | Experimental protocol for DSS-induced colitis. Rats received oral administration of $8 \%$ of DSS from day 0 through day 5 . OEA $(20 \mathrm{mg} / \mathrm{kg}$ ) was intraperitoneally injected once a day from day 0 for 6 days. All rats were euthanized at day 5 .

\section{RNA Isolation and qRT-PCR}

Total RNA of the cultured cells or the rat colon was extracted using the RNeasy Mini Kit (Qiagen, Hilden, Germany), and $1 \mu \mathrm{g}$ of the total RNA was reverse transcribed into cDNA using the PrimeScript ${ }^{\mathrm{TM}}$ RT reagent Kit (Takara Bio, Kusatsu, Japan). PCR was performed using a $25 \mu \mathrm{l}$ reaction mixture containing $1 \mu \mathrm{l}$ of cDNA and $12.5 \mu \mathrm{l}$ Platinum SYBR Green PCR Mix (Life Technologies). $\beta$-actin messenger RNA amplified from the same samples served as an internal control. After initial denaturation at $95^{\circ} \mathrm{C}$ for $2 \mathrm{~min}$, we used a 2 -step cycle procedure (denaturation at $95^{\circ} \mathrm{C}$ for $15 \mathrm{~s}$, annealing and extension at $60^{\circ} \mathrm{C}$ for $1 \mathrm{~min}$ ) for 40 cycles in a 7700 Sequence Detector (Applied Biosystems, Foster City, CA, USA). Gene expression levels were determined using the comparative threshold cycle $(\Delta \Delta \mathrm{Ct})$ method with $\beta$-actin used as an endogenous control. Data were analyzed with Sequences Detection Systems software (Applied Biosystems). The primer sequences are shown in Table 3.

\section{Statistical Analysis}

Data are expressed as mean \pm standard deviation (SD). Parameters among the groups were compared by one-way

TABLE 2 | Colitis histology score. (Singh et al., 2011; Onishi et al., 2015).

\begin{tabular}{|c|c|c|}
\hline Changes & Score & Degree \\
\hline \multirow[t]{4}{*}{ Inflammation severity } & 0 & None \\
\hline & 1 & Mild \\
\hline & 2 & Moderate \\
\hline & 3 & Severe \\
\hline \multirow[t]{4}{*}{ Inflammation extent } & 0 & None \\
\hline & 1 & Mucosa \\
\hline & 2 & Mucosa and submucosa \\
\hline & 3 & Transmural \\
\hline \multirow[t]{5}{*}{ Crypt damage } & 0 & None \\
\hline & 1 & Basal 1/3 damaged \\
\hline & 2 & Basal 2/3 damaged \\
\hline & 3 & Crypts lost; surface epithelium present \\
\hline & 4 & Crypts and surface epithelium lost \\
\hline \multirow[t]{5}{*}{ Percent involvement } & 0 & $0 \%$ \\
\hline & 1 & $1-25 \%$ \\
\hline & 2 & $26-50 \%$ \\
\hline & 3 & $51-75 \%$ \\
\hline & 4 & $75-100 \%$ \\
\hline
\end{tabular}


TABLE 3 | Primer sequences used for qRT-PCR.

\begin{tabular}{|c|c|c|c|}
\hline Gene & Forward primer (5' to $\left.3^{\prime}\right)$ & Reverse primer (5' to $\left.3^{\prime}\right)$ & Accession no. \\
\hline human $\beta$-actin & ccaaccgcgagaagatga & ccagaggcgtacagggatag & XM_035025796.1 \\
\hline human IL-8 & agagtgattgagagtggacc & acttctccacaaccctctg & XM_003832335.5 \\
\hline human IL-1 $\beta$ & aagctgatggccctaaacag & aggtgcatcgtgcacataag & XM_003804503.3 \\
\hline human TNF- $\alpha$ & cagcctcttctccttcctga & gccagagggctgattagaga & XM_003831589.2 \\
\hline rat $\beta$-actin & aagatgacccagatcatgtt & ttaatgtcacgcacgatttc & XM_017294214.2 \\
\hline rat IL-1 $\beta$ & cctatgtcttgcccgtggag & cacacactagcaggtcgtca & XM_032902343.1 \\
\hline rat TNF- $\alpha$ & accacgctcttctgtctactg & cttggtggtttgctacgac & XM_032888689.1 \\
\hline rat TGF- $\beta$ & ctgctgacccccactgatac & agccctgtattccgtctcct & XM_034509875.1 \\
\hline rat IL-8 & cattaatatttaacgatgtggatgcgtttca & gcctaccatctttaaactgcacaat & XM_032916528.1 \\
\hline rat PPAR- $\alpha$ & aatccacgaagcctacctga & gtcttctcagccatgcacaa & XM_034516616.1 \\
\hline rat CD68 & tcacaaaaaggctgccactctt & tcgtagggcttgctgtgctt & NM_001031638.1 \\
\hline
\end{tabular}

analysis of variance, followed by the Holm-Sidak post hoc test. The difference was considered significant at $p<0.05$. All analyses were performed using GraphPad Prism, version 7 (GraphPad software, San Diego, CA, USA).

\section{RESULTS}

\section{OEA Suppresses LPS-Induced Inflammatory Reaction in Vitro}

To investigate the effect of OEA on LPS-TLR4 signaling pathway, we first conducted in vitro experiments using 293/hTLR4AMD2-CD14 cells, which stably express human TLR4A, MD2 and CD14. Treatment with LPS significantly upregulated the expression of TNF- $\alpha$ compared to control, whereas OEA significantly and dose-dependently reduced the expression of TNF- $\alpha$ compared to LPS treatment (Figure 2A). Western blotting demonstrated that treatment with LPS increased phosphorylation of I $\mathrm{B} \alpha \alpha$ compared to control, whereas OEA $(40 \mu \mathrm{M})$ inhibited LPS-induced phosphorylation of IאB $\alpha$ in 293/ hTLR4A-MD2-CD14 cells compared to LPS treatment (Figure 2B).

\section{OEA Suppresses TNF- $\alpha$-Induced Inflammatory Reaction of Caco-2 Cells}

We next investigated the anti-inflammatory effect of OEA on human intestinal epithelial cells (Caco-2 cells). Treatment with TNF- $\alpha$ significantly upregulated the expression of interleukin (IL)- 8 and IL- $1 \beta$ compared to control, and OEA significantly reduced the expression of IL- 8 and IL- $1 \beta$ compared to TNF- $\alpha$ treatment (Figure 3A). Western blotting demonstrated that treatment with TNF- $\alpha$ increased phosphorylation of I $\mathrm{KB} \alpha$ and p65 compared to control, and OEA inhibited TNF- $\alpha$-induced phosphorylation of IKB $\alpha$ and p65 in Caco-2 cells compared to TNF- $\alpha$ treatment (Figure 3B). These results suggest that OEA suppresses the activation of the NF- $\mathrm{KB}$ signaling pathway in intestinal epithelial cells. Moreover, the effect of OEA in reducing the expression of IL- 8 was blocked by MKK866, a PPAR- $\alpha$ antagonist (Figure 3C).
A

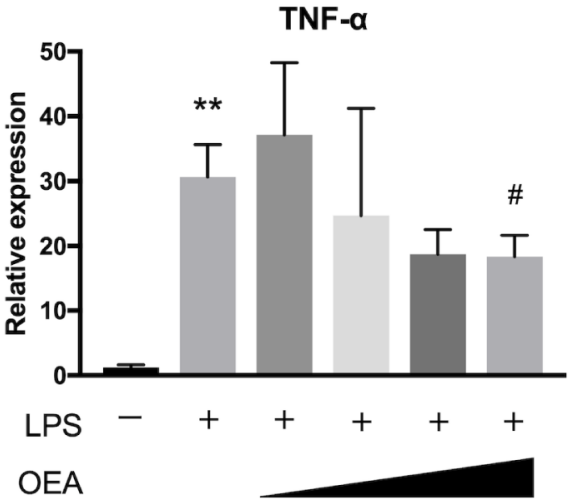

B

OEA

LPS

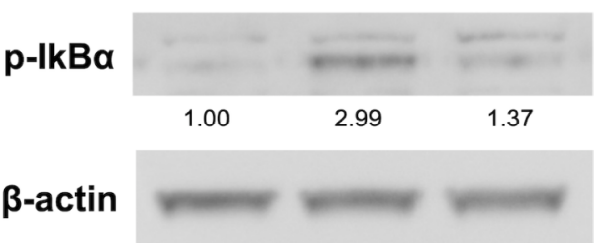

FIGURE 2 | Effect of OEA on inflammatory reactions in vitro. (A) 293/ hTLR4A-MD2-CD14 cells were treated with LPS $(1 \mathrm{ng} / \mathrm{ml})$ for $3 \mathrm{~h}$ after pretreatment with OEA $(2,5,10$, and $40 \mu \mathrm{M})$ for 30 min. Total RNA was isolated and the expression of TNF- $\alpha$ was investigated by qRT-PCR. (B) 293/ hTLR4A-MD2-CD14 cells were treated with LPS (10 $\mathrm{ng} / \mathrm{ml})$ for $2 \mathrm{~h}$ after pretreatment with OEA ( $40 \mu \mathrm{M})$ for $30 \mathrm{~min}$, and the expression of phosphoI $\mathrm{KB} \alpha$ was investigated by Western blotting. Numeric data indicates relative average pixel intensity. The values are the mean $\pm S D(n=3) .{ }^{* *} p<0.01$ versus the Control. ${ }^{\#} p<0.05$ versus LPS.

\section{OEA Suppresses DSS-Induced Colitis in Rats}

We investigated the effects of OEA on DSS-induced colitis in rats. The weight gain in the DSS group was inhibited and the 
A

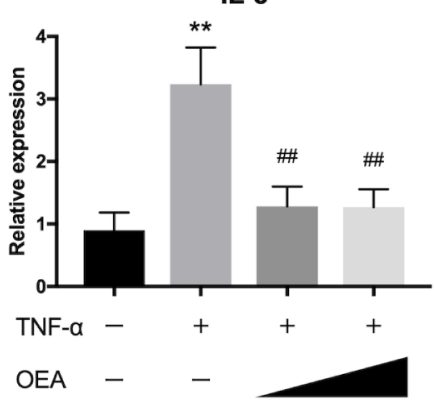

B

OEA

TNF- $\alpha$

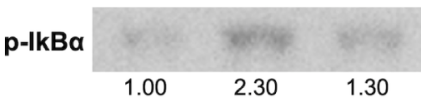

IkB $\alpha$

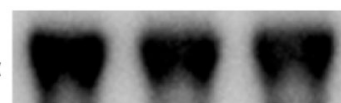

$\beta$-actin

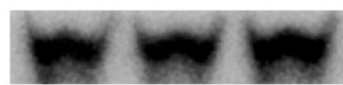

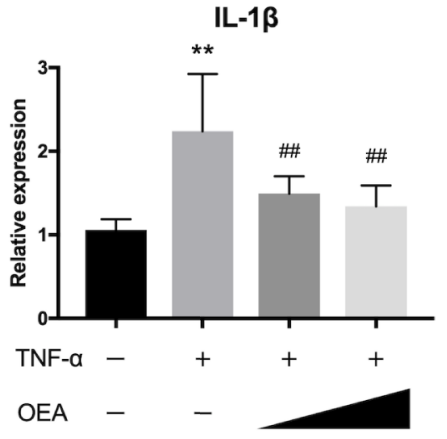

OEA

TNF- $\alpha$

p-p65

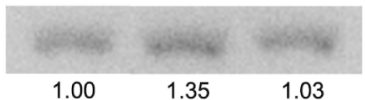

NF-kB

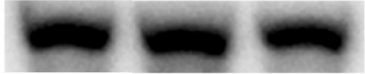

$\beta$-actin

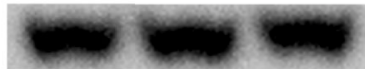

C

IL-8

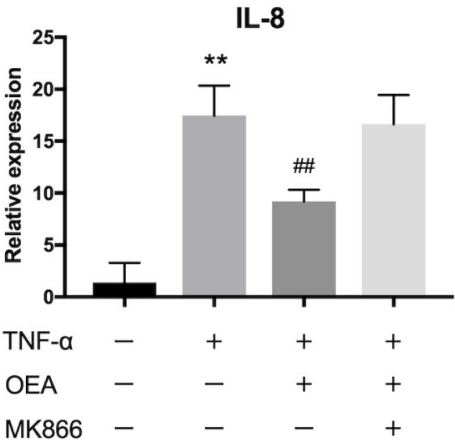

FIGURE 3 | Effect of OEA on inflammatory reaction in Caco-2 cells. (A) Caco-2 cells were treated with TNF- $\alpha$ (5.0 ng/ml) for $1 \mathrm{~h}$ after pretreatment with OEA (10 and $40 \mu \mathrm{M}$ ) for $30 \mathrm{~min}$. Total RNA was isolated and the expression of IL-8 and IL-1 $\beta$ were investigated by GRT-PCR. (B) Caco-2 cells were treated with TNF- $\alpha$ (5.0 $\mathrm{ng} / \mathrm{ml})$ for $15 \mathrm{~min}$ after pretreatment with OEA $(40 \mu \mathrm{M})$ for $30 \mathrm{~min}$, and the expression of phospho-lкB $\alpha$ and phospho-p65 was investigated by Western blotting. Numeric data indicates relative average pixel intensity. (C) Caco-2 cells were treated with TNF- $\alpha(5.0 \mathrm{ng} / \mathrm{ml})$ for $1 \mathrm{~h}$ after pretreatment with OEA (40 $\mu \mathrm{M})$ and MKK866 $(10 \mu \mathrm{M})$ for $30 \mathrm{~min}$. Total RNA was isolated and the expression of IL-8 was investigated by qRT-PCR. The values are the mean \pm SD $(n=3) .{ }^{* *} p<0.01$ versus the Control. ${ }^{\# \#} p<0.01$ versus TNF- $\alpha$.

relative body weight in the DSS group was significantly less than that in the control group from day 2 onward (Figure 4A). However, this change was attenuated by OEA administration, and the relative body weight was significantly increased in the DSS + OEA group compared with the DSS group on day 5. Food intake was significantly reduced in the OEA group, the DSS group, and the DSS + OEA group compared with the control group (Figure 4B). There was no significant difference in food intake among the OEA group, the DSS group, and the DSS + OEA group. DAI gradually increased in the DSS group, but this increase was ameliorated by OEA administration; DAI in the DSS + OEA group was significantly lower than in the DSS group on day 3 onward (Figure 4C). Colon length in the DSS group was significantly shorter than in the control group, but the length was significantly longer in the DSS+OEA group compared with the DSS group (Figure 4D).

\section{Effect of OEA Administration on Histological Score and Infiltration of Inflammatory Cells}

On HE staining, severe transmural inflammation, loss of crypts, and infiltration of inflammatory cells were observed in the DSS group compared to the control group and these findings tended 


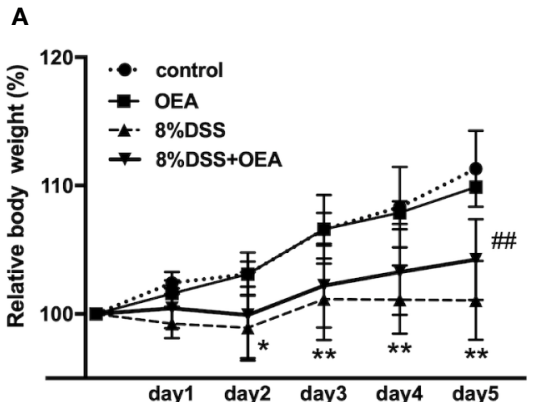

C

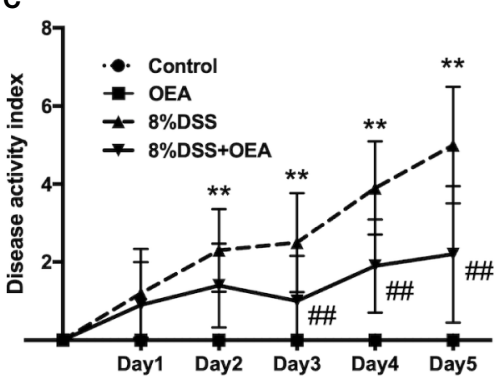

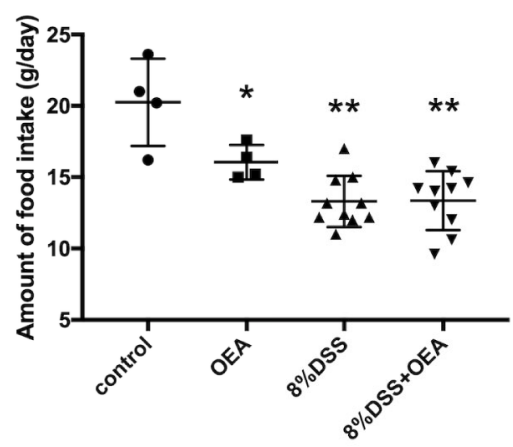

D

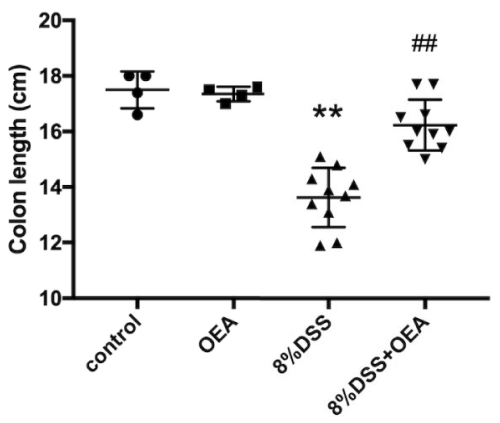

FIGURE 4 | Effect of OEA on DSS-induced colitis in rats. (A) Relative body weight. (B) Amount of food intake. (C) DAl. (D) Colon length. The values are the mean \pm SD ( $n=4$, Control group; $n=4$, OEA group; $n=10$, DSS group and $n=10$, DSS + OEA group). ${ }^{*} p<0.05$ versus Control group. ${ }^{*} p<0.01$ versus Control group. $\#$ \#\# 0.01 versus DSS group.

to be attenuated by the administration of OEA compared to the DSS group (Figure 5A). The histological score in the DSS group was significantly higher than in the control group, and the histological score in the DSS + OEA group tended to be lower than in the DSS group. The infiltration of CD68-positive macrophages was significantly increased in the DSS group compared to the control group; however, OEA administration significantly reduced the infiltration of macrophages compared to the DSS group (Figure 5B). The infiltration of MPO-positive neutrophils was significantly increased in the DSS group compared to the control group; however, OEA administration significantly suppressed this increase compared to the DSS group (Figure 5C).

\section{Effects of OEA Administration on Gene Expression in the Colon}

We next examined the expression of inflammation-related genes in the colon. In the DSS group, mRNA expression levels of inflammatory cytokines, such as IL- $1 \beta$, TNF- $\alpha$, and transforming growth factor (TGF)- $\beta$, were significantly increased compared to the control group. In the DSS + OEA group, the expression levels of these cytokines tended to be reduced (Figures 6B, C) and the expression of IL-1 $\beta$ was significantly reduced compared to the DSS group (Figure 6A). The expression level of IL- 8 tended to be increased in the DSS group compared to the control group and reduced in the DSS + OEA group compared to the DSS group, although not statistically significant (Figure 6D). The expression level of PPAR- $\alpha$ was significantly decreased by the DSS administration compared to the control group, and there was no significant difference in the expression level of PPAR- $\alpha$ between the DSS group and the DSS+OEA group (Figure 6E). The expression level of CD68 was significantly increased in the DSS group compared to the control group, and tented to be decreased in the DSS + OEA group compared to the DSS group (Figure 6F).

\section{DISCUSSION}

In this study, we investigated the anti-inflammatory effects of OEA in vitro and in vivo, and investigated the underlying mechanisms through cell culture experiments. We found that (1) OEA suppressed the LPS-induced inflammatory reaction in vitro, (2) OEA suppressed the TNF- $\alpha$-induced inflammatory reaction in cultured intestinal epithelial cells, and (3) OEA administration ameliorated DSS-induced colitis in rats (Figure 7).

The expression and activation of NF- $\kappa \mathrm{B}$ was strongly induced in the inflamed gut of patients with IBD, and the amount of activated NF- $\mathrm{\kappa B}$ was significantly correlated with the severity of 
A
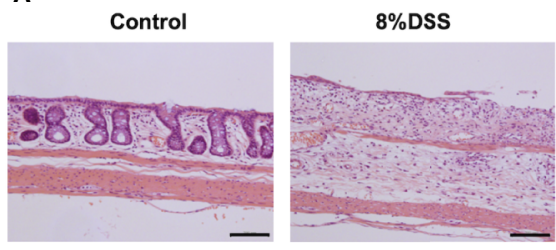

8\%DSS+OEA
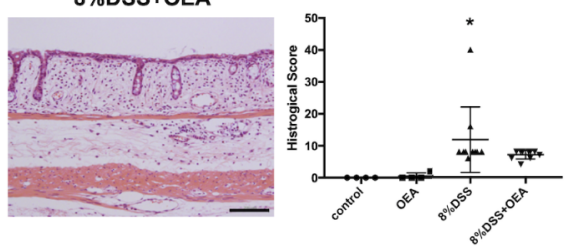

B

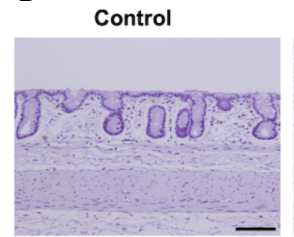

8\%DSS+OEA

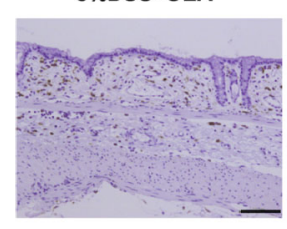

8\%DSS
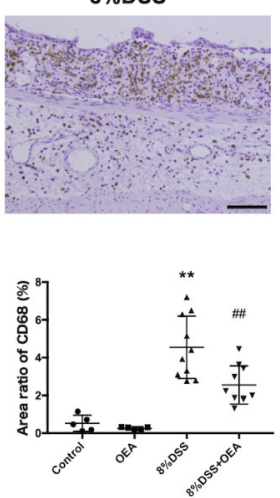

C

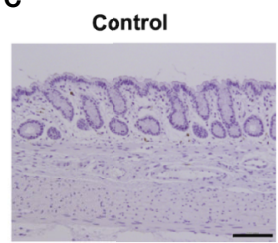

8\%DSS+OEA

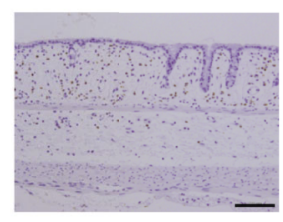

$8 \%$ DSS
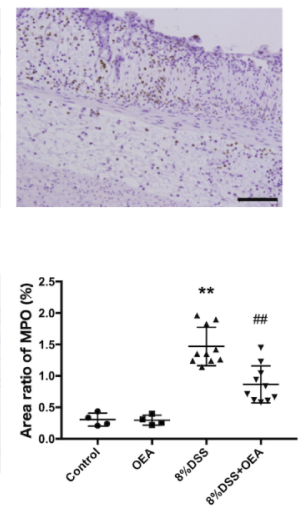

FIGURE 5 | Histological analyses of the colon. (A) HE staining. (B) CD68 expression. (C) MPO expression. The stained areas were measured from the entire colon cross-sectional area. Scale bars, $100 \mu \mathrm{m}$. The values are the mean \pm SD $(n=4$, Control group: $n=4$, OEA group; $n=10$, DSS group and $n=10$, DSS + OEA group). ${ }^{*} p<0.05$ versus Control group. ${ }^{* *} p<0.01$ versus Control group. ${ }^{\# \#} p<0.01$ versus DSS group.

intestinal inflammation (Atreya et al., 2008). OEA has been demonstrated to exert anti-inflammatory effects on LPSinduced monocytes (THP-1) by inhibiting the NF- $\kappa B$ and ERK1/2/AP-1/STAT3 pathways (Yang et al., 2016). In our study, OEA dose-dependently reduced the expression of TNF$\alpha$ and inhibited phosphorylation of I $\mathrm{I} B \alpha$ in LPS-induced 293/hTLR4A-MD2-CD14 cells. Furthermore, OEA reduced the expression of inflammatory cytokines and inhibited phosphorylation of $\mathrm{I} \kappa \mathrm{B} \alpha$ and p65 in TNF- $\alpha$-induced Caco-2 cells. These results suggest that OEA has anti-inflammatory effects, which could be caused by suppressing the activation of the NF- $\kappa B$ signaling pathway in intestinal epithelial cells.

OEA has been reported to function as an agonist for PPAR- $\alpha$ (Fu et al., 2005), TRPV1 (Ahern, 2003), and GPR119 (Lauffer et al., 2009). PPAR- $\alpha$ is highly expressed in intestinal cells (Kimura et al., 2013) and macrophages (Manoharan et al., 2016). It has been demonstrated that the PPAR- $\alpha$ agonist improves murine experimental colitis (Azuma et al., 2010) and deletion or disruption of the PPAR- $\alpha$ pathway alters the function of colonic macrophages (Manoharan et al., 2016). The role of TRPV-1 in the IBD model is controversial (Cseko et al., 2019), and the effects of the GPR119 agonist on the IBD model are unknown. In our study, a PPAR- $\alpha$ antagonist blocked the effect of OEA in reducing the expression of IL- 8 in vitro. This result suggests that the anti-inflammatory effect of OEA in intestinal epithelial cells is mediated by PPAR- $\alpha$ signaling. It has been reported that the PPAR- $\alpha$ mRNA levels were decreased by LPS administration, and different concentrations of OEA upregulated the expression of PPAR- $\alpha$ in cultured monocytes (THP-1 cells, Yang et al., 2016), and it has been reported that administration of OEA significantly increased the mRNA expression levels of PPAR- $\alpha$ in nonalcoholic fatty liver of rats (Li et al., 2015). However, in the present study, the expression of PPAR- $\alpha$ in the colon was decreased by DSS administration, and the OEA administration did not ameliorate this reduction. This result may suggest that the OEA acts as an agonist for PPAR- $\alpha$ without upregulation of PPAR- $\alpha$ expression in the colon.

Macrophages produce pro-inflammatory cytokines in patients with IBD and can induce tissue damage (Steinbach and Plevy, 2014). In our in vivo study, macrophage infiltration was suppressed by the administration of OEA. In patients with UC, the extent of neutrophil infiltration correlates with the 


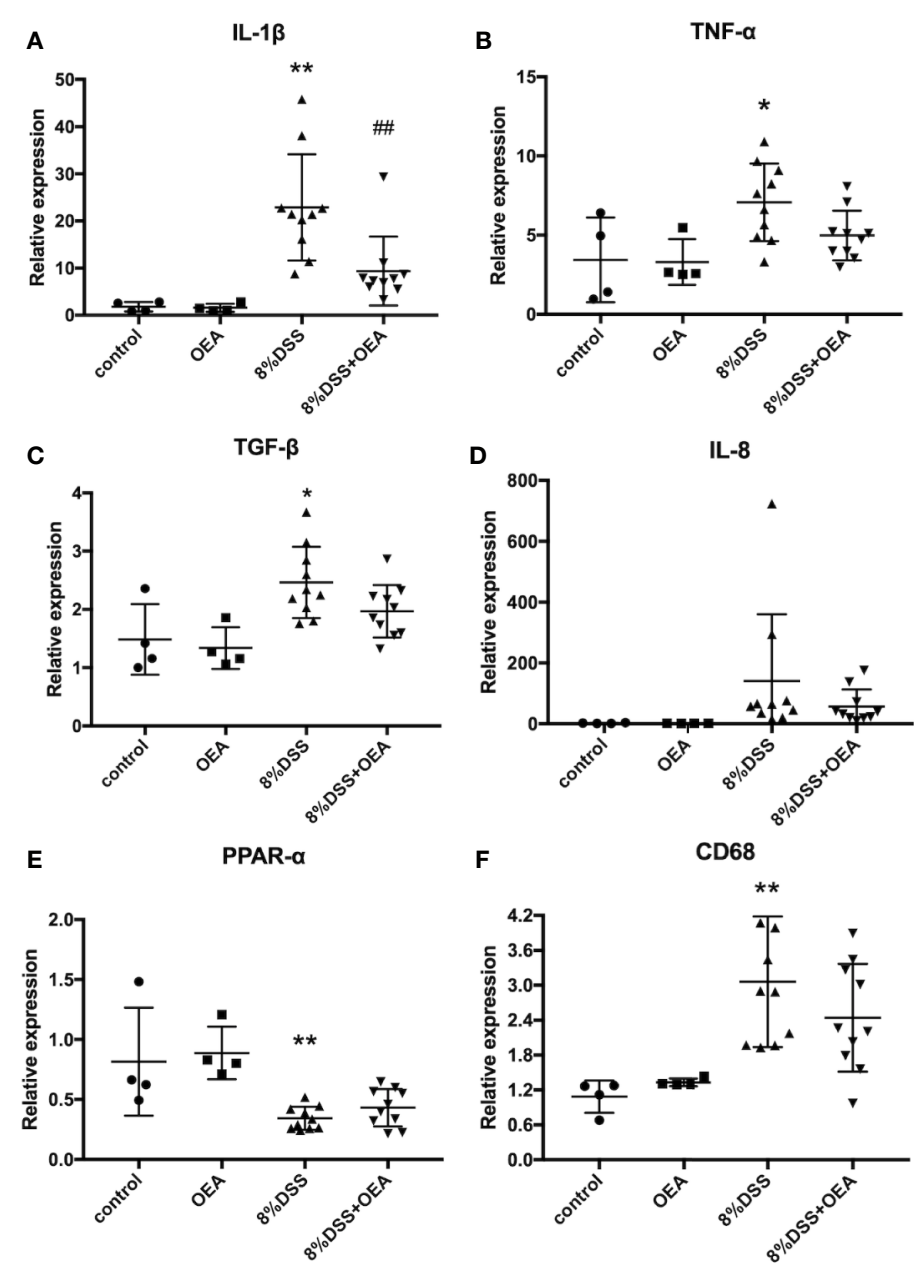

FIGURE 6 | Gene expression analyses of the colon. qRT-PCR analyses of (A) IL-1 $\beta$, (B) TNF- $\alpha$, (C) TGF- $\beta$, (D) IL-8, (E) PPAR- $\alpha$, and (F) CD68. The values are mean \pm SD ( $n=4$, Control group; $n=4$, OEA group; $n=10$, DSS group and $n=10$, DSS + OEA group). * $p<0.05$ versus Control group. ${ }^{* *} p<0.01$ versus Control group. ${ }^{\#} p<0.01$ versus DSS group.

severity of disease (Wera et al., 2016), and IL-8 is mainly a neutrophil chemoattractant that induces the migration of neutrophils from peripheral blood into inflamed tissue (Lee et al., 2018). In the present study, OEA suppressed the expression of IL-8 in Caco-2 cells and neutrophil infiltration in the colon of rats. These results might suggest that OEA suppresses neutrophil infiltration in the colon by inhibiting IL8 expression in intestinal epithelial cells.

It has been reported that administration of OEA reduces food intake (Fu and Gaetani, 2013). In several studies, food intake was significantly reduced by administration of DSS (Ye et al., 2009; Chaudhary et al., 2017). In our study, food intake in the OEA group and the DSS group was significantly reduced compared with that in the control group, as previously reported. However, there was no difference in food intake among the DSS group and the DSS+OEA group. This result might suggest that the antiinflammatory effects of OEA nullify the reduction in food intake caused by DSS administration. In the present study, although significant reduction of food intake in the OEA group was observed compared to the control group, relative body weight was not affected. This may be explained by the influence of OEA on the reduction of spontaneous activity, as previously reported (Proulx et al., 2005).

The therapeutic effects of OEA had previously been reported in small animals with atherosclerosis (Fan et al., 2014), nonalcoholic fatty liver ( $\mathrm{Li}$ et al., 2015), and neuroinflammation (Sayd et al., 2014). In a human clinical trial, the use of OEA for people with obesity improved inflammation and oxidative stress (Payahoo et al., 2018). OEA could have the potential for clinical use in various diseases in the future, and further clinical studies are needed.

This study has several limitations. (1) Although the PPAR- $\alpha$ experiment was conducted in vitro, experiments on other OEA receptors, such as TRPV-1 and GPR119, were not conducted. (2) OEA was administered only intraperitoneally, and oral administration was not conducted in the animal experiment. In many studies, OEA was administrated intraperitoneally and the dosage was typically $5-20 \mathrm{mg} / \mathrm{kg}$. However, in several studies, OEA was administered orally and the dosage was $25-200 \mathrm{mg} / \mathrm{kg}$ 


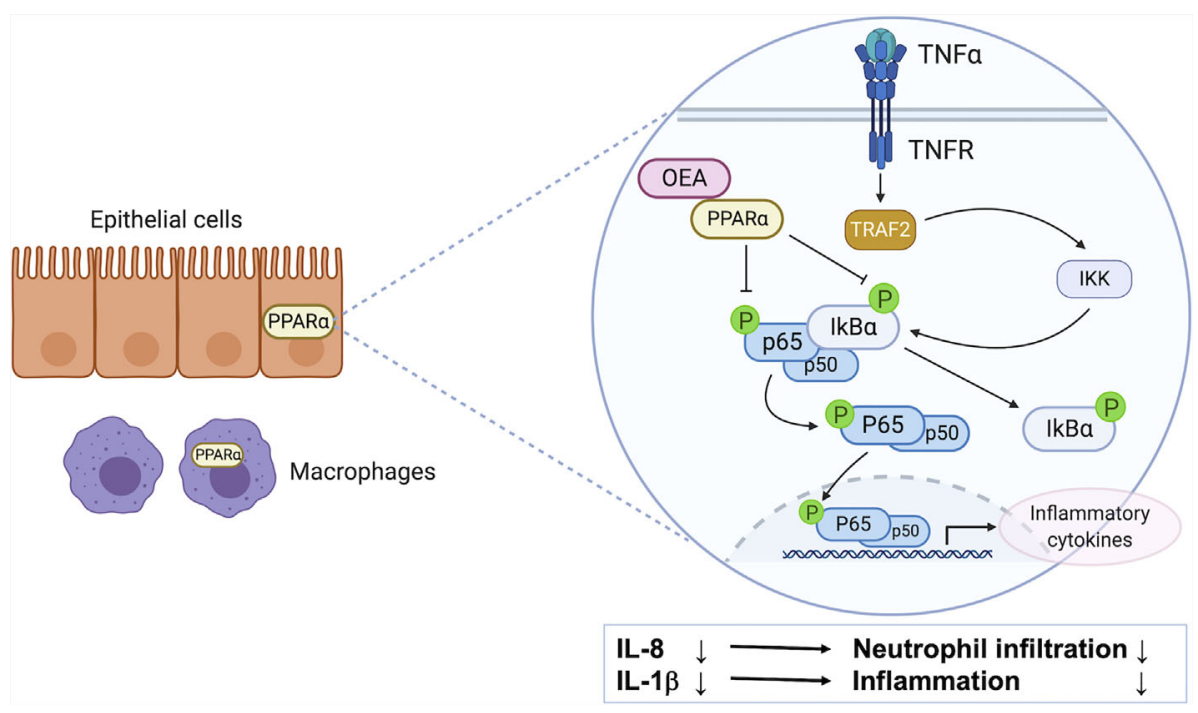

FIGURE 7 | The possible mechanism of anti-inflammatory effect of OEA on colitis. PPAR- $\alpha$ is highly expressed in intestinal epithelial cells and macrophages. OEA inhibits phosphorylation of $\mathrm{I} \mathrm{KB} \alpha$ and $\mathrm{p} 65$, and suppresses the activation of the NF- $\mathrm{KB}$ signaling pathway, resulting in the reduction of the expression of IL-8 and $\mathrm{IL}-1 \beta$ in epithelial cells. IL-8 reduction leads to suppression of neutrophil infiltration, and IL-1 $\beta$ reduction leads to suppression of inflammatory reaction in the colon.

(Nielsen et al., 2004; Oveisi et al., 2004; Thabuis et al., 2011). (3) OEA administration was started at day 0 , before the colitis was developed. (4) Our experimental design was an acute severe colitis model rather than chronic colitis model.

In conclusion, OEA administration ameliorated DSS-induced colitis in rats, possibly by inhibiting the NF- $\kappa B$ signaling pathway through PPAR- $\alpha$ receptors in intestinal epithelial cells. OEA administration could represent a new therapeutic strategy for treating colitis.

\section{DATA AVAILABILITY STATEMENT}

The raw data supporting the conclusions of this article will be made available by the authors, without undue reservation.

\section{ETHICS STATEMENT}

The animal study was reviewed and approved by the Animal Care Unit and Use Committees of Hokkaido University.

\section{REFERENCES}

Ahern, G. P. (2003). Activation of TRPV1 by the satiety factor oleoylethanolamide. J. Biol. Chem. 278, 30429-30434. doi: 10.1074/jbc.M305051200

Ambrosini, A., Zolese, G., Ambrosi, S., Ragni, L., Tiano, L., Littarru, G., et al. (2006). Oleoylethanolamide protects human sperm cells from oxidation stress: studies on cases of idiopathic infertility. Biol. Reprod. 74, 659-665. doi: 10.1095/biolreprod.105.046060

Atreya, I., Atreya, R., and Neurath, M. F. (2008). NF-kappaB in inflammatory bowel disease. J. Intern. Med. 263, 591-596. doi: 10.1111/j.1365-2796.2008.01953.x

\section{AUTHOR CONTRIBUTIONS}

SOt contributed to all experiments, data analysis, and manuscript writing. SOh and NS contributed to conception and design, and final approval of the manuscript. MO, QF, KoY, KeY, and TK contributed to assembly of data and data analysis. All authors contributed to the article and approved the submitted version.

\section{FUNDING}

This study was supported by a Grant-in-Aid for Scientific Research (C) from the Japan Society for the Promotion of Science (JSPS, 20K08347).

\section{ACKNOWLEDGMENTS}

We thank Megumi Kimura, Tomoe Shimazaki, Akiko Hirano, and Osamu Maehara for their technical assistance.

Azuma, Y. T., Nishiyama, K., Matsuo, Y., Kuwamura, M., Morioka, A., Nakajima, H., et al. (2010). PPARalpha contributes to colonic protection in mice with DSSinduced colitis. Int. Immunopharmacol. 10, 1261-1267. doi: 10.1016/ j.intimp.2010.07.007

Brown, J. D., Karimian Azari, E., and Ayala, J. E. (2017). Oleoylethanolamide: A fat ally in the fight against obesity. Physiol. Behav. 176, 50-58. doi: 10.1016/ j.physbeh.2017.02.034

Chaudhary, G., Mahajan, U. B., Goyal, S. N., Ojha, S., Patil, C. R., and Subramanya, S. B. (2017). Protective effect of Lagerstroemia speciosa against dextran sulfate sodium induced ulcerative colitis in C57BL/6 mice. Am. J. Transl. Res. 9, 1792-1800. 
Cluny, N. L., Keenan, C. M., Lutz, B., Piomelli, D., and Sharkey, K. A. (2009). The identification of peroxisome proliferator-activated receptor alpha-independent effects of oleoylethanolamide on intestinal transit in mice. Neurogastroenterol. Motil. 21, 420-429. doi: 10.1111/j.1365-2982.2008.01248.x

Cseko, K., Beckers, B., Keszthelyi, D., and Helyes, Z. (2019). Role of TRPV1 and TRPA1 ion channels in inflammatory bowel diseases: Potential Therapeutic Targets? Pharmaceuticals (Basel). 12, 48. doi: 10.3390/ph12020048

Decara, J. M., Romero-Cuevas, M., Rivera, P., Macias-González, M., Vida, M., Pavón, F. J., et al. (2012). Elaidyl-sulfamide, an oleoylethanolamide-modelled PPAR $\alpha$ agonist, reduces body weight gain and plasma cholesterol in rats. Dis. Model Mech. 5, 660-670. doi: 10.1242/dmm.009233

Di Paola, M., Bonechi, E., Provensi, G., Costa, A., Clarke, G., Ballerini, C., et al. (2018). Oleoylethanolamide treatment affects gut microbiota composition and the expression of intestinal cytokines in Peyer's patches of mice. Sci. Rep. 8, 14881. doi: 10.1038/s41598-018-32925-x

Fan, A., Wu, X., Wu, H., Li, L., Huang, R., Zhu, Y., et al. (2014). Atheroprotective effect of oleoylethanolamide (OEA) targeting oxidized LDL. PLoS One 9, e85337. doi: 10.1371/journal.pone.0085337

Feagan, B. G., Sandborn, W. J., Gasink, C., Jacobstein, D., Lang, Y., Friedman, J. R., et al. (2016). Ustekinumab as induction and maintenance therapy for Crohn's Disease. N. Engl. J. Med. 375, 1946-1960. doi: 10.1056/NEJMoa1602773

$\mathrm{Fu}$, J., and Gaetani, S. (2013). Oleylethanolamide regulates feeding and body weight through activation of the nuclear receptor PPAR- $\alpha$. Nature 425, 90-93. doi: 10.1038/nature01921

Fu, J., Oveisi, F., Gaetani, S., Lin, E., and Piomelli, D. (2005). Oleoylethanolamide, an endogenous PPAR-alpha agonist, lowers body weight and hyperlipidemia in obese rats. Neuropharmacology 48, 1147-1153. doi: 10.1016/j.neuropharm.2005.02.013

Fumery, M., Singh, S., Dulai, P. S., Gower-Rousseau, C., Peyrin-Biroulet, L., and Sandborn, W. J. (2018). Natural history of adult ulcerative colitis in population-based cohorts: a systematic review. Clin. Gastroenterol. Hepatol. 16, 343-356.e3. doi: 10.1016/j.cgh.2017.06.016

Gaetani, S., Oveisi, F., and Piomelli, D. (2003). Modulation of meal pattern in the rat by the anorexic lipid mediator oleoylethanolamide. Neuropsychopharmacology 28, 1311-1316. doi: 10.1038/sj.npp.1300166

Gonzalez-Aparicio, R., Blanco, E., Serrano, A., Pavon, F. J., Parsons, L. H., Maldonado, R., et al. (2017). The systemic administration of oleoylethanolamide exerts neuroprotection of the nigrostriatal system in experimental Parkinsonism. Int. J. Neuropsychopharmacol. 17, 455-468. doi: 10.1017/S1461145713001259

Grill, M., Hogenauer, C., Blesl, A., Haybaeck, J., Golob-Schwarzl, N., Ferreiros, N., et al. (2019). Members of the endocannabinoid system are distinctly regulated in inflammatory bowel disease and colorectal cancer. Sci. Rep. 9, 2358. doi: 10.1038/s41598-019-38865-4

Kimura, R., Takahashi, N., Lin, S., Goto, T., Murota, K., Nakata, R., et al. (2013). DHA attenuates postprandial hyperlipidemia via activating PPARalpha in intestinal epithelial cells. J. Lipid Res. 54, 3258-3268. doi: 10.1194/jlr.M034942

Lauffer, L. M., Iakoubov, R., and Brubaker, P. L. (2009). GPR119 is essential for oleoylethanolamide-induced glucagon-like peptide-1 secretion from the intestinal enteroendocrine L-cell. Diabetes 58, 1058-1066. doi: 10.2337/db08-1237

Lee, S. H., Kwon, J. E., and Cho, M. L. (2018). Immunological pathogenesis of inflammatory bowel disease. Intest. Res. 16, 26-42. doi: 10.5217/ir.2018.16.1.26

Li, L., Li, L., Chen, L., Lin, X., Xu, Y., Ren, J., et al. (2015). Effect of oleoylethanolamide on diet-induced nonalcoholic fatty liver in rats. J. Pharmacol. Sci. 127, 244-250. doi: 10.1016/j.jphs.2014.12.001

Manoharan, I., Suryawanshi, A., Hong, Y., Ranganathan, P., Shanmugam, A., Ahmad, S., et al. (2016). Homeostatic PPARalpha signaling limits inflammatory responses to commensal microbiota in the intestine. J. Immunol. 196, 4739-4749. doi: 10.4049/ jimmunol.1501489

Martin, J. C., Bériou, G., and Josien, R. (2016). Dextran sulfate sodium (DSS)induced acute colitis in the rat. Methods Mol. Biol. 1371, 197-203. doi: 10.1007/ 978-1-4939-3139-2_12

Nielsen, M. J., Petersen, G., Astrup, A., and Hansen, H. S. (2004). Food intake is inhibited by oral oleoylethanolamide. J. Lipid Res. 45, 1027-1029. doi: 10.1194/ jlr.C300008-JLR200

Onishi, R., Ohnishi, S., Higashi, R., Watari, M., Yamahara, K., Okubo, N., et al. (2015). Human amnion-derived mesenchymal stem cell transplantation ameliorates dextran sulfate sodium-induced severe colitis in rats. Cell Transplant. 24, 2601-2614. doi: 10.3727/096368915X687570
Oveisi, F., Gaetani, S., Eng, K. T., and Piomelli, D. (2004). Oleoylethanolamide inhibits food intake in free-feeding rats after oral administration. Pharmacol. Res. 49, 461-466. doi: 10.1016/j.phrs.2003.12.006

Pandurangan, A. K., Mohebali, N., Norhaizan, M. E., and Looi, C. Y. (2015). Gallic acid attenuates dextran sulfate sodium-induced experimental colitis in BALB/c mice. Drug Des. Devel. Ther. 9, 3923-3934. doi: 10.2147/DDDT.S86345

Payahoo, L., Khajebishak, Y., Asghari Jafarabadi, M., and Ostadrahimi, A. (2018). Oleoylethanolamide supplementation reduces inflammation and oxidative stress in obese people: a randomized clinical trial. Adv. Pharm. Bull. 8, 479487. doi: 10.15171/apb.2018.056

Payahoo, L., Khajeblshak, Y., Alivand, M. R., Solelmanzade, H., Alipour, S., Barzegari, A., et al. (2019). Investigation the effect of oleoylethanolamide supplementation on the $\mathrm{T}$ abundance of Akkermansia muciniphila bacterium and the dietary intakes in people with obesity: A randomized clinical trial. Appetite 141, 104301. doi: 10.1016/j.appet.2019.05.032

Peyrin-Biroulet, L., Loftus, E. V.Jr, Colombel, J. F., and Sandborn, W. J. (2010). The natural history of adult Crohn's disease in population-based cohorts. Am. J. Gastroenterol. 105, 289-297. doi: 10.1038/ajg.2009.579

Proulx, K., Cota, D., Castañeda, T. R., Tschöp, M. H., D’Alessio, D. A., Tso, P., et al. (2005). Mechanisms of oleoylethanolamide-induced changes in feeding behavior and motor activity. Am. J. Physiol. Regul. Integr. Comp. Physiol. 289, R729-R737. doi: 10.1152/ajpregu.00029.2005

Sandborn, W. J., Su, C., Sands, B. E., D’Haens, G. R., Vermeire, S., Schreiber, S., et al. (2017). Tofacitinib as induction and maintenance therapy for ulcerative colitis. N. Engl. J. Med. 376, 1723-1736. doi: 10.1056/NEJMoa1606910

Sayd, A., Anton, M., Alen, F., Caso, J. R., Pavon, J., Leza, J. C., et al. (2014). Systemic administration of oleoylethanolamide protects from neuroinflammation and anhedonia induced by LPS in rats. Int. J. Neuropsychopharmacol. 18:pyu111. doi: 10.1093/ijnp/pyul11

Singh, K., Chaturvedi, R., Barry, D. P., Coburn, L. A., Asim, M., Lewis, N. D., et al. (2011). The apolipoprotein E-mimetic peptide COG112 inhibits NFkappaB signaling, proinflammatory cytokine expression, and disease activity in murine models of colitis. J. Biol. Chem. 286, 3839-3850. doi: 10.1074/jbc.M110. 176719

Steinbach, E. C., and Plevy, S. E. (2014). The role of macrophages and dendritic cells in the initiation of inflammation in IBD. Inflamm. Bowel Dis. 20, 166-175. doi: 10.1097/MIB.0b013e3182a69dca

Thabuis, C., Destaillats, F., Lambert, D. M., Muccioli, G. G., Maillot, M., Harach, T., et al. (2011). Lipid transport function is the main target of oral oleoylethanolamide to reduce adiposity in high-fat-fed mice. J. Lipid Res. 52, 1373-1382. doi: 10.1194/ jlr.M013391

Tutunchi, H., Saghafi-Asl, M., and Ostadrahimi, A. (2020). A systematic review of the effects of oleoylethanolamide, a high-affinity endogenous ligand of PPAR$\alpha$, on the management and prevention of obesity. Clin. Exp. Pharmacol. Physiol. 47, 543-552. doi: 10.1111/1440-1681.13238

Wera, O., Lancellotti, P., and Oury, C. (2016). The dual role of neutrophils in inflammatory bowel diseases. J. Clin. Med. 5:118. doi: 10.3390/jcm5120118

Yang, L., Guo, H., Li, Y., Meng, X., Yan, L., Dan, Z., et al. (2016). Oleoylethanolamide exerts anti-inflammatory effects on LPS-induced THP-1 cells by enhancing PPARalpha signaling and inhibiting the NF-kappaB and ERK1/2/AP-1/STAT3 pathways. Sci. Rep. 6, 34611. doi: 10.1038/srep34611

Ye, Z., Liu, Z., Henderson, A., Lee, K., Hostetter, J., Wannemuehler, M., et al. (2009). Increased CYP4B1 mRNA is associated with the inhibition of dextran sulfate sodium-induced colitis by caffeic acid in mice. Exp. Biol. Med. (Maywood). 234, 605-616. doi: 10.3181/0901-RM-1

Conflict of Interest: The authors declare that the research was conducted in the absence of any commercial or financial relationships that could be construed as a potential conflict of interest.

Copyright (C) 2020 Otagiri, Ohnishi, Ohara, Fu, Yamamoto, Yamamoto, Katsurada and Sakamoto. This is an open-access article distributed under the terms of the Creative Commons Attribution License (CC BY). The use, distribution or reproduction in other forums is permitted, provided the original author(s) and the copyright owner(s) are credited and that the original publication in this journal is cited, in accordance with accepted academic practice. No use, distribution or reproduction is permitted which does not comply with these terms. 